\title{
Retirement of a distinguished researcher - Prof. Upali S. Amarasinghe
}

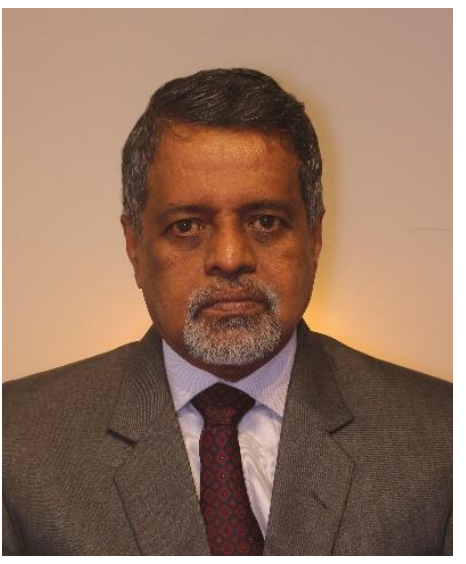

Prof. Upali Sarath Amarasighe, an eminent researcher in fisheries and aquatic sciences retired from the university service on the $9^{\text {th }}$ February 2020 after serving 28 years. At the time of retirement, he was a Senior Professor at the Department of Zoology and Environmental Management of the University of Kelaniya.

This issue of the Sri Lanka Journal of Aquatic Sciences is dedicated to Prof. Amarasinghe for his continuous contribution to fisheries and aquatic sciences both locally and globally for 41 years.

He obtained his BSc (Honours) from the University of Kelaniya, Sri Lanka in 1978, MSc from the University of Wales, U.K. in 1984, PhD from the University of Ruhuna, Sri Lanka in 1991 and DSc from Bangor University, U.K. in 2010. He was awarded the DSc (Honoris Causa) by the University of Ruhuna, Sri Lanka in 2019.

Before joining the University of Kelaniya in November 1992, he has served as a Scientific Officer at the National Science Council of Sri Lanka and a Research Officer at the Ministry of Fisheries and the National Aquatic Resources Research and Development Agency for 13 years.

Prof. Amarasinghe has been contributing to the Sri Lanka Journal of Aquatics Sciences continuously from its inaugural volume up to now. He was a member of the Editorial Board from 1996 to 2009 and the Editor in Chief from 2010 to 2018. Since 2019 he serves as an Honorary Editor. He played a leading role in getting this journal indexed in Aquaculture and Fisheries Abstracts of FAO and Master Journal list (Web of Science) of Thomson Reuters and presently of Clarivate Analytics.

In addition, he has served as the Editor in Chief of the Journal of Science of the University of Kelaniya, and was a member of the Editorial Board of the Journal of National Science Foundation, Sri Lanka which is indexed in the Science Citation Index Expanded. He was also a member of the Editorial Board of three other journals namely, the Asian Fisheries Science, Taprobanica-the Journal of Asian Biodiversity and the Journal of the National Aquatic Resources Agency, Sri Lanka. Presently, he is one of the Associate Editors of Asian Fisheries Science.

He has carried out vast amount of research in fisheries and aquatic sciences, particularly on inland fisheries, fish stock assessment and fisheries management. He has published 149 research papers in refereed journals and was the co-editor 09 books/monographs. He has presented more than 80 papers in international and national research conferences. He has disseminated his knowledge as a keynote speaker and an invited guest speaker in many research symposia. He has also been a resource person in numerous local and international training workshops in fisheries and aquatic sciences.

Prof. Amarasinghe has provided his service as a referee of manuscripts submitted to nearly 50 scientific journals, which include prestigious journals indexed in the Science Citation Index with a very high 
impact factor and also to large number of research conferences, both local and foreign.

His research has been cited by many researchers, which is evident by his h-index of 25 and i10-index of 66. Among the fisheries scientists in Sri Lanka, he has the highest h-index and the highest i10-index. He is the most cited fisheries scientist in Sri Lanka with more than 2300 citations. During the past 07 years, he has more than 100 citations per year.

$\mathrm{He}$ has contributed significantly for the development of the Department of Zoology and Environmental Management (DZEM) of the University of Kelaniya by purchasing limnological equipment and two field vehicles through the two research grants he obtained from Australian Centre for International Agricultural Research (ACIAR) and European Union under its INCO-DC programme. These equipment and field vehicles helped the staff and students of the DZEM immensely in conducting field research. However, due to some personal reasons, the University Authorities in 2012, took these vehicles to the common vehicle pool of the University, which significantly affected the research of the staff and students of the DZEM. Nevertheless, DZEM has so far produced the highest number of research publications in the University for which Prof Amarasinghe contributed significantly.

Prof. Amarasinghe was a member of the first Research Council of the University of Kelaniya. Together with Prof. M.J.S. Wijeyaratne, the Founder Chairman of this Council, he significantly contributed to enhance the research culture of the university, which resulted in the University of Kelaniya becoming the $3^{\text {rd }}$ best university in Sri Lanka in July 2017 according to Webometrics ranking.

He has contributed immensely for human resources development in the field of fisheries and Aquatic Sciences by supervising many postgraduate students. He has been the supervisor for $11 \mathrm{PhDs}$ and 17 MPhils. In addition, he has supervised the research projects of $14 \mathrm{MSc}$ students. He is the academic who has supervised the highest number of $\mathrm{PhDs}$ and MPhils in Sri Lanka in the field of fisheries and aquatic sciences.
Prof. Amarasinghe is a member of several professional associations and a Fellow of the National Academy of Sciences, Sri Lanka (NASSL). He was one of the Founder Joint Secretaries of the Sri Lanka Association for Fisheries and Aquatic Resources (SLAFAR) as well as of the Sri Lanka Forum for Small-Scale Fisheries. He was also the President of SLAFAR and the General Secretary and Secretary/Foreign Relations of the NASSL.

He has provided his service as a consultant to many international organizations and institutions including the Food and Agriculture Organization of the United Nations (FAO), United Nations Industrial Development Organization, Asian Institute of Technology, Harper Adams University of UK, Network of Aquaculture Centres in the Asia-Pacific, University of Stirling, Worldwide Fund for Nature in Pakistan and International Development Research Centre of Canada. He was also a member of the IPFC working party of experts on inland fisheries of the FAO.

He has served as a member of Governing Board of the National Research Council of Sri Lanka and many Committees of the Sri Lanka Council for Agricultural Research Policy, National Science Foundation, Biodiversity Secretariat of the Ministry of Environment and IUCN-Sri Lanka. He has also been a Consultant to National Science and Technology Commission and National Aquaculture Development Authority. Recently he has been appointed as a member of the Scientific Technical Committee of the National Aquatic Resources Research and Development Agency of Sri Lanka.

Prof. Amarasinghe has won many awards for his research. He has received Presidential Research Awards in six years. He was the recipient of the Best Young Scientist award in the field of Biology awarded by the Third world Academy of Sciences, Trieste, Italy. He has won two life-time awards, viz the Committee of Vice Chancellors and Directors (CVCD) Excellence Award for the most outstanding senior scientist in biological sciences and the GRC Award for the most outstanding scientist in biological sciences awarded by Sri Lanka Association for Advancement of Science. 
He has won Vice-Chancellors Awards 19 times which included the awards for the most outstanding scientist in the university, the most outstanding researcher in the Faculty of Science, being among the top 10 researchers of the university, bringing honour to the university and publishing the highest number of publications in the journals indexed in the Science Citation Index. He is the academic who has won the highest number of Vice-Chancellor's Awards in the University of Kelaniya.

Even after retirement Prof. Amarasinghe continues to supervise several $\mathrm{PhD}$ and MPhil students and serve as an Honorary member of the editorial board of Sri Lanka Journal of Aquatic Sciences, referee of manuscripts submitted to many scientific journals, visiting professor of several universities, a member of the executive committees of several professional associations and a consultant to several national and international institutions.

I wish him a peaceful and healthy retirement.

Snr. Prof. M. M. Pathmalal

Editor in Chief

Sri Lanka Journal of Aquatics Sciences 